\title{
A comparison of benthic microfloral production on the West and Gulf coasts of the United States: an introduction to the dynamic K-systems model
}

\author{
Gary P. Shaffer \\ Coastal Ecology Institute and Department of Experimental Statistics, Louisiana State University, Baton Rouge, \\ Louisiana 70803-7503, USA
}

\begin{abstract}
Intensive month-long studies of benthic microfloral productivity were conducted during summer in California (Mugu Lagoon) and Louisiana (Barataria Estuary), USA, coastal wetland ecosystems. In general, fluctuations in production during the month approximated those measured in other studies over an entire year (with daily values ranging from 0 to $1554 \mathrm{mg} \mathrm{C} \mathrm{m}^{-2}$ ). Collectively, productivity was controlled primarily by different types of disturbance: tidal currents, meteorological and manmade waves, and direct and indirect disturbance by macrofauna were most important. To explore the potential of $\mathrm{K}$-systems analysis as a modeling tool, simple models restricted to physical variables were developed for each site. These models suggested that certain variables such as tidal currents and waves functioned primarily as controllers (e.g. acted to decrease productivity), while others such as light and temperature functioned as modifiers (e.g. modified the severity of the decrease). The effects of modifying variables are highly consistent, granted interrelationships with other variables are considered. If modifying variables are isolated (as in parametric statistics) their effects appear spurious. In general, the K-systems models suggested that benthic microfloral productivity cannot be accurately described by static models.
\end{abstract}

\section{INTRODUCTION}

Several investigators (Leach 1970, Riznyk et al. 1978, Onuf et al. 1979, Colijn \& de Jonge 1984) have made regional comparisons of benthic microfloral productivity. These comparisons were derived from annual estimates which were based on hourly measurements carried out on a limited number of days each month. It has recently been shown (Rizzo \& Wetzel 1985, Shaffer \& Onuf 1985) that these estimates are of questionable value, since the entire range of variation can be accounted for by sampling and conversion errors.

Benthic microflora are capable of extremely short turnover times, characteristically between 1 and $4 \mathrm{~d}$. To obtain a reliable estimate of production and the factors controlling productivity, measurements must be made often enough to encompass the full range of variation in productivity, and in the variables that influence productivity. Recently, such studies have been carried out in estuarine systems on the West and Gulf coasts of the United States (Shaffer \& Cahoon 1987, Shaffer 1988 [preceding article]). Both of these studies followed changes in productivity and several other variables for a 1 mo period during summer. The purposes of this report are (1) to compare, between regions, benthic microfloral productivity, and the factors governing that productivity, and (2) to demonstrate the usefulness of K-systems analysis as a dynamic modeling tool.

\section{MATERIALS AND METHODS}

One of the studies was conducted in the eastern arm of Mugu Lagoon, Ventura county, California $\left(34^{\circ} 06^{\prime} \mathrm{N}\right.$, $\left.119^{\circ} 05^{\circ} \mathrm{W}\right)$. The lagoon is affected by a mesotidal range of $2.4 \mathrm{~m}$ and is open to the ocean year around; semi-diurnal tidal flushing occurs to varying degrees. In the absence of large rivers, salinity approximates that of the open ocean, $33 \%$, (Shaffer \& Onuf 1983). The second study was conducted on the barrier island Grand Terre, located in Barataria Estuary, Louisiana $\left(29^{\circ} 16^{\prime} \mathrm{N}, 89^{\circ} 57^{\prime} \mathrm{W}\right)$. Grand Terre is affected by a microtidal range of $0.61 \mathrm{~m}$ and experiences diurnal tides. The salinity of the bay averages $22 \%$ and ranges from 12 to $27 \%$ (Byrne et al. 1976).

The gross productivity of the benthic microflora and 
the respiration of the benthic community were determined by incubating intact sediment cores $3.4 \mathrm{~cm}$ diameter, $0.5 \mathrm{~cm}$ deep) in stirred light-dark chambers at the sample sites, and measuring changes in dissolved oxygen (Shaffer \& Cahoon 1987). For Mugu Lagoon, daily productivity measurements based on 28 cores were made at a subtidal site consisting of very poorly sorted sand, and an intertidal site consisting of poorly sorted muddy sand (Folk 1968). For Barataria Estuary, daily productivity measurements based on 40 cores were made at an intertidal site consisting of wellsorted fine sand, and a subtidal site consisting of fine muddy sands covered by a thin veneer (1 to $2 \mathrm{~mm}$ ) of mud, resulting from suspension deposition.

After each incubation, the cores from each chamber were pooled for a cumulative measurement of the concentration of chlorophyll $a$ in each chamber. Photosynthetically active radiation was measured in $\mu \mathrm{E} \mathrm{m}^{-2} \mathrm{~s}^{-1}$ with a LI-COR 185-B quantum meter. Other variables measured during both studies were water temperature next to the sediment cores, initial dissolved oxygen concentration, benthic community respiration, mean tidal range, hours of subaerial daytime exposure, and for Barataria Estuary astronomical and meteorological (increased water level caused by southerly winds [setup] and decreased water level caused by northerly winds [set-down]) tide, salinity, and biological activity. The results from multichannel information analysis and K-systems analysis for Mugu Lagoon (Shaffer \& Cahoon 1987) and Barataria Estuary (Shaffer 1988) are compared here. Basically, multichannel information analysis is a multivariate time series analysis designed to find information peaks in a data set. This type of analysis relies on periodicities in a data set and is therefore time dependent. Basically, K-systems analysis (KSA) is a maximum entropy stepwise regression that employs events rather than variables as its fundamental unit. K-systems analysis isolates important events, whether periodic or aperiodic, and is thus event driven rather than time driven. Stepwise KSA is designed to isolate the minimal number of events which account for a maximal portion of the behavior of a dependent variable. A software package which performs KSA (algorithms developed by Jones 1984 , 1985a, b, c) should be available by late 1988 (marketer as yet unknown; contact author for details)

In addition to the stepwise analysis, KSA was used here to develop predictive models for each site. The models were kept simple by reducing the total number of possible factors. This was accomplished by limiting each model to physical variables and factor 'states' Factor states occur when all of the variables are specified in each factor, as opposed to 'substates' which contain only a subset of the variables. For example, consider a system containing the variables $V_{1}, V_{2}$, and
$V_{3}$, each taking the value 0 or 1 Examples of states are $\left(V_{1}=0, V_{2}=0, V_{3}=0\right.$, or $V_{1}=1, V_{2}=0, V_{3}=0$, etc. $)$ and examples of substates are $\left(\mathrm{V}_{1}=0, \mathrm{~V}_{3}=1\right.$, or $\mathrm{V}_{2}=$ $1, V_{3}=1$, or $V_{3}=0$, etc.); there are many more substates in a system than states. In most ecosystem models, data is assumed to fit specific mathematical structure. In K-systems modeling, structure is discovered rather than assumed. The models presented here are entirely dependent upon the data from Shaffer \& Cahoon (1987) and Shaffer (1988).

\section{RESULTS AND DISCUSSION}

\section{Light intensity}

For both regions, photosynthetic rate increased at low light intensities and was maximal over a wide range of high intensities. The saturating light level at Mugu Lagoon, $1260 \mu \mathrm{E} \mathrm{m}^{-2} \mathrm{~s}^{-1}$, was almost 3 times higher than for Barataria Estuary $\left(460 \mu \mathrm{E} \mathrm{m}^{-2} \mathrm{~s}^{-1}\right)$, reflecting adaptation to higher water turbidity in the estuary. The water overlying the sample sites at Mugu Lagoon was characteristically clear, with an average insolation reaching the benthos of $1028 \mu \mathrm{E} \mathrm{m} \mathrm{m}^{-2} \mathrm{~s}^{-1}$ ( $\pm 210 \mathrm{SE}$ ). In contrast, the water overlying the sample sites at Barataria Estuary was very turbid (e.g. Secchi depths as low as $15 \mathrm{~cm}$ ), with an average insolation reaching the benthos of $469 \mu \mathrm{E} \mathrm{m}^{-2} \mathrm{~s}^{-1}$ ( $\pm 29.3 \mathrm{SE}$ ). For Mugu Lagoon, removing the variation in productivity caused by light resulted in distinct sinusoidal patterns with $14 \mathrm{~d}$ frequencies (Shaffer \& Cahoon 1987). Similar patterns were not found when the same technique was applied to the Barataria Estuary productivity data, because (1) light intensities during the incubation periods often approximated saturating light levels, and (2) meteorological events, which affected productivity greatly, did not display a sinusoidal pattern.

\section{Spatial and temporal patterns}

Daily productivity was estimated using the formula for 'Actual' productivity in Shaffer \& Onuf (1985, p. 227). Estimated daily productivity (Fig. 1) experienced tremendous fluctuations during the 1 mo periods, approximating the annual variation previously measured (Pomeroy 1959, Leach 1970, Riznyk \& Phinney 1972, Cadée \& Hegeman 1974, 1977, Joint 1978, Riznyk et al. 1978, van Es 1982, Shaffer \& Onuf 1983, Colijn \& de Jonge 1984, Rizzo \& Wetzel 1985). This high day to day variability exemplifies the difficulty of sampling during 'mean' conditions, especially if sampling is restricted to 1 or $2 \mathrm{~d}$ each month. An extreme existed for the sand site at Barataria Estuary 
(Fig. 1c) where the mean $\left(0.45 \mathrm{~g} \mathrm{C} \mathrm{m}^{-2} \mathrm{~d}^{-1}\right)$ is a composite of many high and low values, and relatively few intermediate values. The variability was not as severe at Mugu where sampling 4 times within $14 \mathrm{~d}$ periods, each month, would likely produce a reliable estimate of annual productivity and maximize the information concerning the environmental variables governing productivity. This is because the system spans its full range of variation within $14 \mathrm{~d}$ periods (see information peak at $1 / 14=0.07$ cycles $d^{-1}$ in Fig. 2a).

For a given number of samples (e.g. 4), sampling within $14 \mathrm{~d}$ periods would also increase the chances of measuring the full range of daily production at Barataria Estuary (see all possible $14 \mathrm{~d}$ periods in Fig. 1c, d), but would not ensure encompassing the full range of variation of the factors controlling that produc-

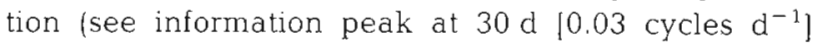
periods in Fig. 2b). This is because large meteorological events during the summer are episodic. Such events destroy, or at least distort, the regular periodicity associated with astronomical tides. Nevertheless, concentrating all monthly samples within a narrower period would still improve the chances of determining what factors control the highly labile productivity. At

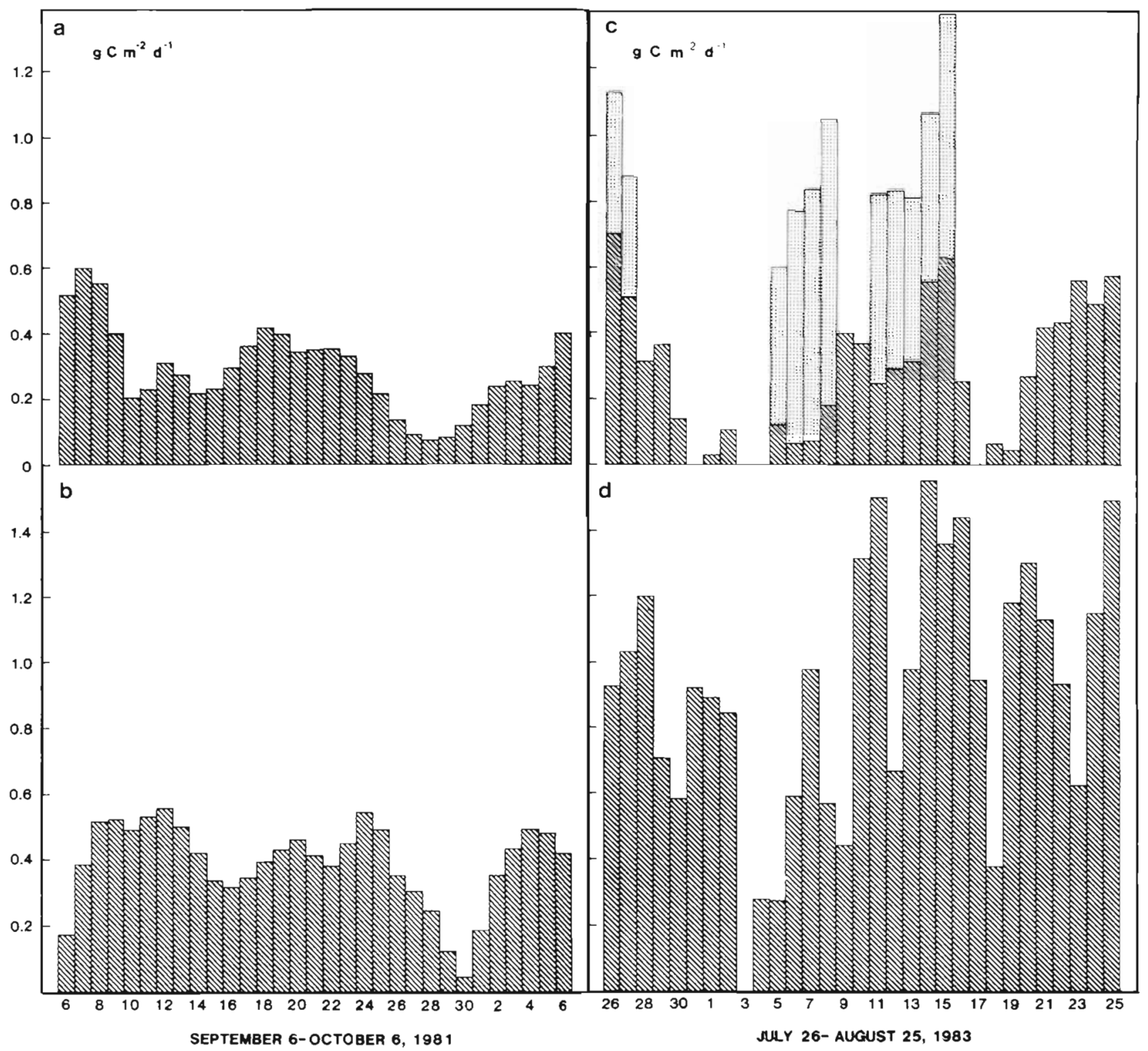

Fig. 1. Estimated daily production $\left(\mathrm{g} \mathrm{C} \mathrm{m}^{-2}\right.$ ) at (a) sand site and (b) muddy sand site for Mugu Lagoon, and (c) sand site and (d) muddy sand site for Barataria Estuary ([c] and [d] redrawn from Shaffer 1988). Diagonal shading: measurements made around noontime; stippling: measurements made during late afternoon when the sand site (Barataria Estuary) was exposed 

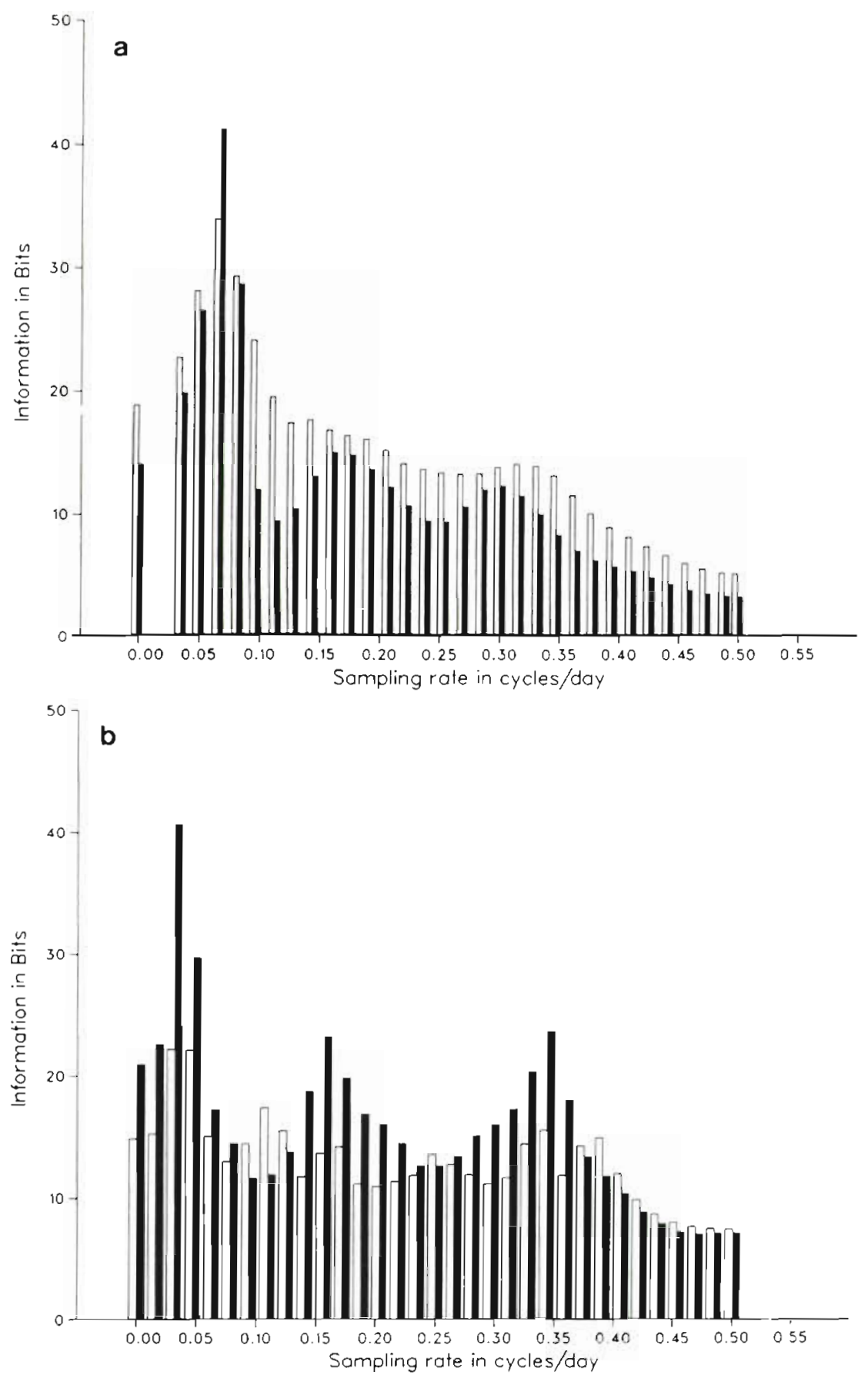

Fig. 2. Total information for all variables combined at different frequencies for (a) Mugu Lagoon and (b) Barataria Estuary (redrawn from Shaffer \& Cahoon 1987 and Shaffer 1988). Black bars: sand response; open bars: muddy sand response

no point during either month-long study did productivity remain stable, or undergo a steady increase or decrease for more than a few days. In short, conditions either conducive or adverse to productivity for more than a few consecutive days are unlikely Therefore, to best measure fluctuations in productivity, and to determine what factors control these fluctuations, measurements should be concentrated into narrow temporal periods.

\section{Dynamic K-systems model}

$\mathrm{K}$-systems state models are dynamic in that variables may express a different effect in each factor. Previously (Shaffer \& Cahoon 1987. Shaffer 1988), stepwise KSA was performed to isolate the minimum set of factors which accounted for most ( 77 to $99 \%$ ) of the behavior in productivity. In general, the factors extracted by the stepwise procedure each contained several variables, 
indicating no single variable limited productivity. Had a single variable consistently limited productivity, we would have expected the factors to contain only that variable. In such a situation a factor and a variable would be synonymous.

When several variables occupy each factor, and the stepwise reconstruction requires only a few factors, it is difficult to dissect out the relative influence of the individual variables. What is needed is a factorial arrangement enabling systematic examination of all levels of a particular variable while the levels of other variables are held constant. This is precisely what comprises the K-systems state model. This type of model can be employed to predict behavior of the dependent variable for all possible events. Perhaps more importantly, such a model can improve our understanding of interrelationships among the variables comprising each factor. For example, if factor effects remain constant over different levels of a particular variable, then the variable is ineffectual. At the other extreme, if a particular level of a variable is consistently associated with a particular behavior of the dependent variable, across levels of the other variables, then that variable is likely to function as a controlling variable. Between the 2 extremes lie variables which modify rather than control factor effects: particular levels of modifying variables act to consistently inflate or deflate, but not to produce, particular factor effects. The behavior of a modifying variable will become clear as we interpret the $\mathrm{K}$-systems state models for the 4 sites.

The simplest KSA state model occurs for the Mugu Lagoon sand site (Table 1a) which contains 8 possible states (that is, there are only 8 possible ways of combining high or low levels of tidal range, light intensity, and water temperature [ 3 variables, 2 categories each, yielding $2^{3}$ combinations]). Along with each factor in Table 1 is the effect of that factor on productivity and the resulting value of productivity. Inspection of the model for the Mugu Lagoon sand site reveals that the largest increases in productivity were accompanied by low tidal ranges (i.e. current speeds; Shaffer \& Cahoon 1987), high light intensities, and high water temperatures (Factor 3, Table 1a), and the greatest decreases were accompanied by the opposite (Factor 6). Although high tidal range was always accompanied by decreases in productivity (Factors 1, 2, 5, 6), these decreases were greatly modified by light intensity and water temperature. For example, the modifying effect of light can be seen by comparing Factor 1 with 2, 3 with 4,5 with 6 , and 7 with 8 (Table 1a). Out of context, modifying variables appear to have highly inconsistent effects; for example, both positive and negative productivity occur under high light (Factors 1 , $3,5,7$ ), but when placed into context (i.e. when interrelationships are considered) the effects are consistent.
This is precisely why pairwise relationships isolated in the laboratory often do not extrapolate ecologically (although they are of obvious importance physiologically): pairwise relationships rarely exist in nature.

The K-systems state model for the Barataria Estuary sand site is both more complicated and more interesting. The model contains 24 possible states ( 3 variables with 2 levels, 1 variable with 3 levels, yielding $2^{3} \times 3$ combinations). The greatest decreases in productivity were accompanied by high wave height, low light intensity, high tide height, and set-up conditions (Factor 2, Table 1b), and the greatest increases were accompanied by the opposite (Factor 23). As with tidal range at Mugu, wave height (which acts as a disturbance when high) appears to function as a controlling variable, by producing consistent decreases in productivity (for 10 of the 12 factors: 1, 2, 5, 6, 9, 10, 13, 14, 17 , $18,21,22)$. Only when all other variables were favorable to productivity (Factors 13, 21) were high waves accompanied by increases in productivity. As for Mugu Lagoon, light functions as a modifier rather than a controller (compare Factor 1 with 2, 3 with 4, .., 23 with 24); high light intensities consistently deflated decreases and inflated increases. Taken out of context, the effect of high light (Column 1 and 3) appears extremely inconsistent, since it is associated with effects from -72 to $+131 \%$. Non-linearities pervade the model, perhaps best exemplified by comparing Factors 4 and 5 which produce identical effects, yet contain opposite values for all variables except meteorological tide. It appears that the negative effect of high wave energies and the positive effects of high light and low tide (Factor 5) are balanced by the positive effect of low waves, and the negative effects of low light and high tides (Factor 4 ).

For the Mugu Lagoon muddy sand site the K-systems state model based on physical variables was generally, though not totally, consistent with past interpretation (Shaffer \& Cahoon 1987). Light intensity appears to be the most important variable influencing productivity, with low light (Table 2a, Factors 2, 4, 6, . ., 16) always accompanied by decreases in productivity and high values associated with increases for 6 of the 8 states. Both water temperature and subaerial exposure had highly consistent effects as modifiers (for temperature compare Factors 1 to 4 with 5 to 8 and 9 to 12 with 13 to 16 , and for exposure compare Factor 1 with 9,2 with 10 , 3 with $11, \ldots, 8$ with 16). In contrast with the Mugu Lagoon sand site, tidal range appeared spurious in the model. In addition, specific pieces of information were not resolved when the model was limited to physical variables (Table 2a). For example, the reconstruction based on the complete data set (Shaffer \& Cahoon 1987) indicated that high subaerial exposure combined with high light was associated with large decreases in 
Table 1. K-systems state models for sand sites at (a) Mugu lagoon and (b) Barataria Estuary. Factors are constrained to high (H) and low (L) categories of the physical. variables tidal range (TR, $\mathrm{m}$ ), light $\left(\mu \mathrm{E} \mathrm{m} \mathrm{m}^{-2} \mathrm{~s}^{-1}\right)$, water temperature (Temp, ${ }^{\circ} \mathrm{C}$ ), wave height $(\mathrm{WH}, \mathrm{cm})$, tide height $(\mathrm{TH}, \mathrm{cm})$, and meteorological tides $(\mathrm{MT}, \mathrm{cm})$ which include an intermediate (I) category

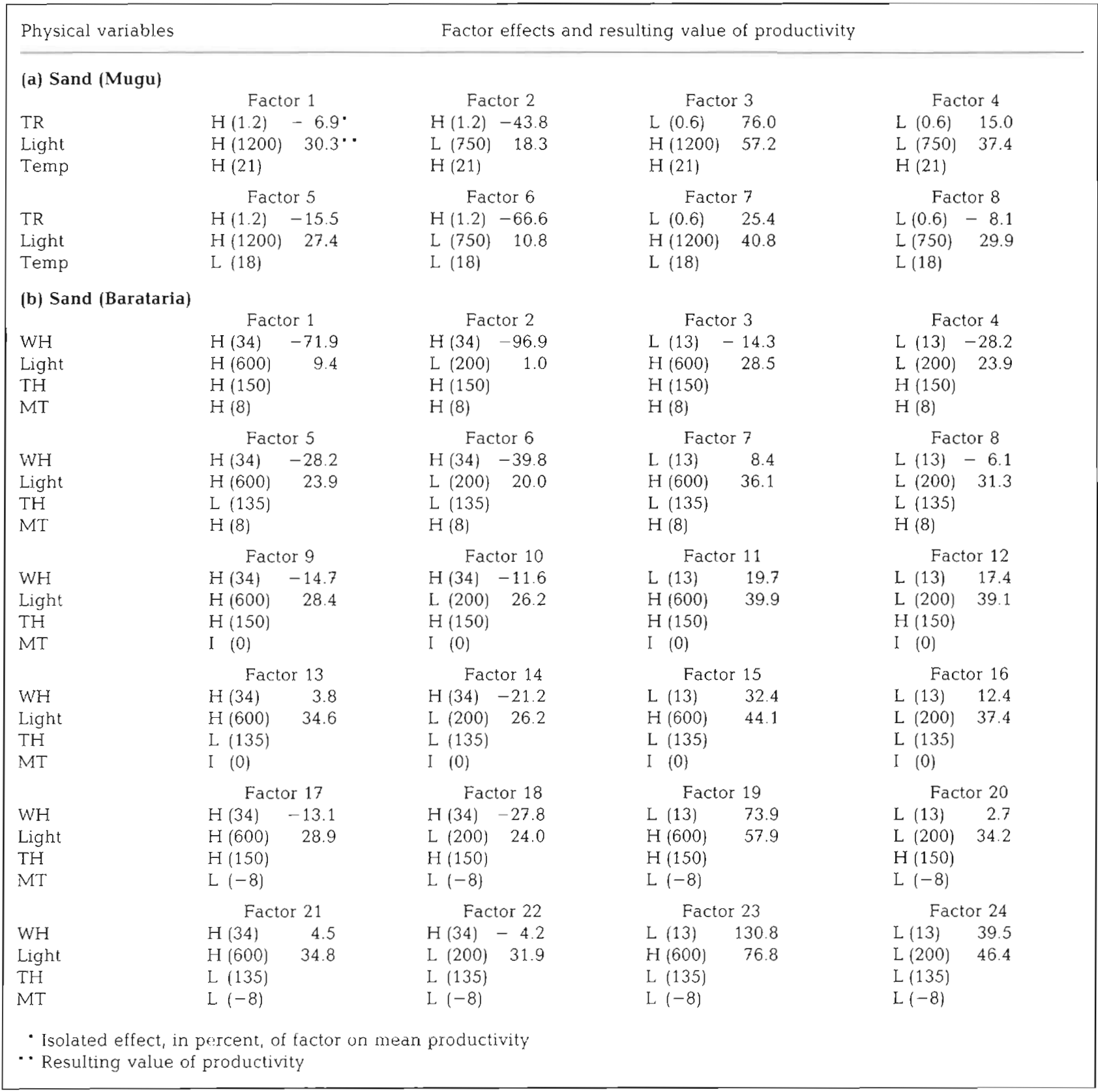

productivity, presumably as a result of desiccation; without standing crop this effect was not resolved.

The muddy sand site in Barataria Estuary was more protected from physical disturbance than that of Mugu. Consequently, the state model based exclusively on physical variables (Table $2 b$ ) failed to resolve the more consistent factor effects described previously (Shaffer 1988). Physical processes in this relatively lower energy area interact strongly with biological processes (e.g. the ingress and egress of fishes). Nevertheless, certain effects were resolved; the greatest decreases in productivity were associated with set-ups and high tides, especially combined with low light intensity (Table $2 b$, Factor 2) and the greatest increases were associated with calm or set-down conditions combined with low tides and high light (Factors 7, 11). Factor 6 is an anomaly perhaps related to an interaction with a biological process not included in the model.

In short, it appears that easily monitored physical variables may produce realistic estimates of difficult to 
Table 2. K-systems models for muddy sand sites at (a) Mugu lagoon and (b) Barataria Estuary. Factors are constrained to high (H) and low (L) categories of the physical variables tidal range $(\mathrm{TR}, \mathrm{m})$, light $\left(\mu \mathrm{E} \mathrm{m} \mathrm{m}^{-2} \mathrm{~s}^{-1}\right)$, water temperature (Temp, $\left.{ }^{\circ} \mathrm{C}\right)$, daytime subaerial exposure $($ Expo, h), tide height $(\mathrm{TH}, \mathrm{cm})$, and meteorological tides $(\mathrm{MT}, \mathrm{cm})$ which include an intermediate (I) category

Physical variables

(a) Muddy sand (Mugu)

\begin{tabular}{lll} 
& \multicolumn{2}{c}{ Factor 1} \\
TR & $\mathrm{H}(1.2)$ & 45.1 \\
L.ight & $\mathrm{H}(1250)$ & 59.2 \\
Temp & $\mathrm{H}(21)$ \\
Expo & $\mathrm{H}(8)$ &
\end{tabular}

TR

Light

Temp

Expo

TR

Light

Temp

Expo

TR

Light.

Temp

Expo

\section{Factor 5 \\ $\mathrm{H}(1.2) \quad 2.6$ \\ $\mathrm{H}(1250) \quad 41.8$ \\ L (19) \\ $\mathrm{H}(8)$}

Factor 9

$\mathrm{H}(1.2) \quad 17.6$

$\mathrm{H}(1250) \quad 47.9$

$\mathrm{H}(21)$

$\mathrm{H}(4)$

Factor 13

H (1.2) -10.8

$\mathrm{H}(1250) \quad 36.4$

I (19)

L (4)

Factor effects and resulting value of productivity

(b) Muddy sand (Barataria)

\begin{tabular}{llr} 
& \multicolumn{2}{c}{ Factor 1} \\
Light & $H(640)$ & -51.9 \\
TH & $H(150)$ & 39.9 \\
MT & H $(8)$ \\
& \multicolumn{2}{c}{ Factor 5} \\
Light & H $(640)$ & 18.9 \\
TH & H $(150)$ & 98.5 \\
MT & I $(0)$ \\
& \multicolumn{2}{c}{ Factor 9} \\
Light & H $(640)$ & 1.0 \\
TH & H $(150)$ & 83.7 \\
MT & L $(-8)$
\end{tabular}

Factor 2

L. (300) -100.0

$\mathrm{H}(150) \quad 0.0$

$\mathrm{H}(8)$

Factor 6

L (300) 88.6

$\mathrm{H}(150) \quad 156.3$

I $(0)$

\section{Factor 10}

L. (300) -22.2

$\mathrm{H}(150) \quad 64.5$

L $(-8)$
Factor 3

L (0.6) 20.6

L (1250) 49.1

$H(21)$

$\mathrm{H}(8)$

Factor 7

$\mathrm{H}(0.6) \quad 9.9$

L (1250) 44.8

L (19)

$\mathrm{H}(8)$

Factor 11

L (0.6) $\quad 5.8$

$\mathrm{H}(1250) \quad 43.1$

$\mathrm{H}(21)$

L (4)

Factor 15

L (0.6) $\quad-7.0$

$\mathrm{H}(1250) \quad 37.9$

L (19)

L (4)

Factor 3

$\mathrm{H}(640) \quad 12.8$

L (135) 93.5

$\mathrm{H}(8)$

Factor 7

$\mathrm{H}(640) \quad 55.3$

L (135) 128.8

I (0)

Factor 11

$\mathrm{H}(640) \quad 57.7$

L (135) 130.7

L $(-8)$
Factor 4

L (0.6) -1.9

L (700) 40.0

$\mathrm{H}(21)$

$\mathrm{H}(8)$

Factor 8

L (0.6) -16.1

L. (700) 34.2

L (19)

$\mathrm{H}(8)$

Factor 12

L $(0.6)-12.6$

L (700) 35.6

$\mathrm{H}(21)$

L (4)

Factor 16

L (0.6) -44.1

$\mathrm{L}(700) \quad 22.8$

L (19)

L (8)

- Isolated effect, in percent, of factor on mean productivity

- Resulting value of productivity

measure ecosystem functions such as primary productivity. The more protected the area is from physical influences, the coarser the resolution of the prediction. Obviously, attempting to model difficult-to-measure variables with easily measurable ones is not novel. The problem with many previous attempts was procedural in that no method was available to model dynamic behavior. An extreme example can be found in my own research (Shaffer \& Onuf 1983), where I conclude that each of 6 independent variables was most important in explaining variation in productivity during at least 1 mo of an annual study. This conclusion was based on the highest partial correlation for monthly multiple regressions of productivity on these variables. In actuality, these correlations (computed across all data points for each month) represent diluted, overall effects which may have had little to do with large fluctuations over shorter periods. Dynamic behavior simply cannot be captured with a static model: assumptions about constraints are unrealistic. Fortunately, it appears that we are now in a position to model dynamic behavior of ecosystem function.

In summary, for all 4 sites discussed in this report, $\mathrm{K}$ systems analysis indicated that no single variable limits productivity. Rather, variables combine to form factors, and these factors change over time. Presumably, ecological systems contain a finite set of factors (i.e. each ecosystem function is controlled by a finite number of factors and each of these is comprised of a finite number of variable combinations). The set of 
responses of an ecosystem function to the set of all possible factors or events could be represented by a comprehensive set of rules which might eventually approximate a grammar: Just as words integrate to produce specific thoughts, variables integrate to produce specific events. Variables (like words) are plastic in that effects are dependent upon context. A limiting variable may be similar to the verb in a sentence which controls much of the impact, yet is clearly madified by its surroundings. This concept is somewhat analogous to Hutchinson's (1957) hypervolume niche theory, in which a niche exists as an abstract hypervolume situated in some space whose axes correspond to the potentially limiting physical and biological variables. The difference is that here we are addressing the behavioral changes within the hypervolume and the approximate interrelationships among variables which produce those changes. Currently, it would be premature to produce a set of assembly rules from the KSA state models presented here (even for the most physically driven Barataria sand site). These models are deliberately simplified to demonstrate the plausibility of such an approach and to act as precursors and incentives to more realistic models. A comprehensive model would require controlled multivariate manipulations in the laboratory with perhaps finer cluster structure for certain variables to resolve more specific effects, combined with more detailed (seasonal) temporal measurements in the field (as discussed in Shaffer 1988).

Acknowledgements. The research on Mugu Lagoon was sponsored in part by NOAA, National Sea Grant College Program Department of Commerce, under Grants No. 04-7158-44121 and NA80AA-D-00120 Projects No. R/CZ33A and 52 through the California Sea Grant Program, and the California State Resources Agency. Chris Onuf led these projects. The research on Barataria Estuary was sponsored by Louisiana State University's Alumnj Federation Fellowship and Department of Marine Sciences. I am indebted to Harry Schafer for permission to use the Grand Terre Facility and to Vince Guillory and Mark Chatry for their assistance during the study. I thank James Gosselink, Bush Jones, Peter Cahoon, Larry Rouse, James Grace, James Geaghan, James Brannon, Irv Mendelssohn, and John Day Jr. for valuable discussion and for their (plus 3 anonymous reviewers') comments on the manuscript

\section{LITERATURE CITED}

Byme, P., Borengasser, M., Drew, G., Muller, R. A., Smith, B. L., Wax, C. (1976). Barataria Basin: hydraulic and climatologic processes. Louisiana State Univ., Sea Grant Publ. LSU-T-76-010
Cadée, G. C., Hegeman, J. (1974). Primary production of the benthic microflora living on tidal flats in the Dutch Wadden Sea. Neth. J. Sea Res. 8: 260-291

Cadée, G. C., Hegeman, J. (1977). Distribution of primary production of the benthic microflora and accumulation of organic matter on a tidal flat area, Balgzand, Dutch Wadden Sea. Neth. J. Sea Res. 11: 24-41

Colijn, F., Jonge, V. N. de (1984). Primary production of microphytobenthos in the Ems-Dollard estuary. Mar. Ecol. Prog. Ser. 14: 185-196

Es, F. B. van (1982). Community metabolism of intertidal flats in the Ems-Dollard estuary. Mar. Biol. 66: 95-108

Folk, R. L. (1968). Petrology of sedimentary rocks. Hemphills, Austin

Hutchinson, G. E. (1957). Concluding remarks. Cold Spring Harbor Sym. Quant. Biol. 22: 415-427

Joint, I. R. (1978). Microbial production of an estuarine mudflat. Estuar. coast. mar. Sci. 7: 185-195

Jones, B. (1984). Determination of unbiased reconstructions. Int. J. gen. Syst. 10: 169-176

Jones, B. (1985a). Reconstructability considerations with arbitrary data. Int. J. gen. Syst. 11: 143-151

Jones, B. (1985b). A greedy algorithm for a generalization of the reconstruction problem. Int. J. gen. Syst. 11: 63-68

Jones, B. (1985c). Reconstructability analysis of general functions. Int. J. gen. Syst. 11 133-142

Leach, J. H. (1970). Epibenthic algal production in an intertidal mudflat. Limnol. Oceanogr. 15: 514-521

Onuf, C. P., Quammen, M. L., Shaffer, G. P., Peterson, C. H., Chapman, J., Cermak, J., Holmes, R. W. (1979). An analysis of the values of central and southern California coastal wetlands. In: Greeson, P. W., Clark, J. R., Clark, J. E. (eds.) Functions and values: the state of our understanding. American Water Resources Ass., Minneapolis, p. 186-199

Pomeroy, L. R. (1959). Algal productivity in salt marshes of Georgia. Limnol. Oceanogr. 4: 386-397

Riznyk, R., Phinney, H. K. (1972). Manometric assessment of interstitial microalgae production in two estuarine sediments. Oecologia (Berl.) 10: 193-203

Riznyk, R., Eddens, J. I., Libby, R. C. (1978). Production of epibenthic diatoms in a southern California impounded estuary. J. Phycol. 14: 273-279

Rizzo, W. M., Wetzel, R. L. (1985). Intertidal and shoal benthic community metabolism in a temperate estuary: studies of spatial and temporal scales of variability. Estuaries 8 : 342-351

Shaffer, G. P. (1988). K-systems analysis for determining the factors influencing benthic microfloral productivity in a Louisiana estuary, USA. Mar. Ecol. Prog. Ser. 43: 43-54

Shaffer, G. P., Cahoon, P. (1987). Extracting information from ecological data containing high spatial and temporal variability: benthic microfloral production. Int. J. gen. Syst. 14: $107-123$

Shaffer, G. P., Onuf, C. P. (1985). Reducing the error in estimating annual production of benthic microflora: hourly to monthly rates, patchiness in space and time. Mar. Ecol. Prog. Ser. 26: 221-231

Shaffer, G. P., Onuf, C. P. (1983). An analysis of factors influencing the primary production of the benthic microflora. Neth. J. Sea Res. 17: 126-144 